\title{
INDENIZAÇÕES POR MORTE NO TRANSPORTE RODOVIÁRIO DE CARGAS: ESTUDO ESTATÍSTICO NO PERÍODO COMPREENDIDO ENTRE 2015 E 2018
}

\author{
C.A.Queiroz ${ }^{*}$; D.A.Farias ${ }^{1}$; M.V. Nascimento ${ }^{1}$ \\ 1-Faculdade de Tecnologia de São José dos Campos - Professor Jessen Vidal \\ Av. Cesare Mansueto Giulio Lattes, 1350 - Eugênio de Melo, São José dos Campos/SP, \\ CEP.: 12247-014, Brasil, - Telefone: (12)3905-2423 \\ *carlos.queiroz@fatec.sp.gov.br
}

\begin{abstract}
RESUMO: O presente trabalho trata do estudo da variação da quantidade de indenizações pagas por morte no transporte rodoviário de cargas, dentro de um contexto de ações tomadas pelo poder público para mitigar a grande quantidade de acidentes rodoviários provocados por caminhoneiros. Considera-se neste certame as variáveis: a evolução da frota nacional de caminhões e a evolução das rodovias pavimentadas no âmbito nacional. Para este trabalho foi utilizado o modelo de regressão linear, onde são unificados os estudos de modelagem e dados estatísticos, meio pelo qual se analisou a influência dos fatores supracitados sobre as indenizações pagas por morte relativas ao transporte rodoviário. Como resultado dessa modelagem, entende-se que o aumento da frota de caminhões, bem como o crescimento da malha rodoviária pavimenta, não têm influência significativa nas variações das indenizações pagas. Considerando como hipótese mais plausível os efeitos benéficos da lei do descanso.
\end{abstract}

PALAVRAS-CHAVE: indenizações; morte; rodoviário; caminhões.

SUMMARY: This paper deals with the study of the variation of the amount of indemnities paid for death in the road transportation, within a context of actions taken by the public power to mitigate the great amount of road accidents caused by truck drivers. The variables considered in this event are: the evolution of the national fleet of trucks and the evolution of the paved roads in the national scope. It is in this scenario that the linear regression model was used, in which the modeling and statistical data were consolidated, through which the influence of the factors mentioned above on the death benefits related to road transportation were analyzed. As result of this modeling, it is understood that the increase in the truck fleet, as well as, the growth of the road network, don't have a significant influence on the variations of the indemnities paid. Considering as a more plausible hypothesis the beneficial effects of the law of rest.

KEYWORDS: indemnities; death; road transport; trucks.

\section{INTRODUÇÃO}

Silva (2011, p. 42) descreve como principais fatores de risco para acidentes de trabalho envolvendo motoristas:

"As falhas mecânicas do equipamento de trabalho, o veículo; condições precárias das rodovias; privação de sono; fadiga e o uso abusivo de anfetaminas e cafeína como estratégias para manterem-se acordados, a pressão para o cumprimento dos prazos e horários de trabalho impostos pelas empresas".

Levantamentos revelam que $35 \%$ dos acidentes rodoviários no Brasil envolvem veículos de carga, que representam apenas 3,22\% da frota nacional. Dos acidentes com caminhões, $5 \%$ resultam 
em mortes; dos caminhoneiros envolvidos, $15 \%$ estavam dirigindo há mais de quatro horas contínuas (POLÍCIA RODOVIÁRIA FEDERAL, 2012).

As causas principais de acidentes nas rodovias brasileiras em 2012, eram: a fadiga (18\%) e o sono (42\%), compreendendo uma estatística de $60 \%$ de todos os acidentes. Onde se evidencia que 93\% eram provocadas por falha humana (ABRAMET, 2012).

De acordo com o IPEA (2015a), em 2014 um acidente rodoviário custou em média à sociedade brasileira o montante de $\mathrm{R} \$ 261.689,00$, enquanto que acidentes com vítimas fatais apresentou um custo médio de $\mathrm{R} \$ 664.821,00$.

Mediante a estes dados, a Lei $\mathrm{n}^{\circ}$ 12.619/2012, conhecida como a Lei do Descanso foi regulamentada pela resolução 405/2012 do Conselho Nacional de Trânsito (CONTRAN), no dia $17 / 06 / 2012$. Visando estabelecer um mecanismo institucional com competência para mudar tal realidade e proteger uma categoria vulnerável, tanto, nos aspectos trabalhistas, quanto social.

A Lei do Descanso determina que os motoristas têm o direito a repouso de 11 horas por dia, além do descanso de 30 minutos a cada 4 horas ininterruptas de direção. Assim, o tempo máximo de direção diária será de dez horas. A norma é direcionada ao motorista que transporta carga com peso bruto superior a 4.536 quilos, ao profissional de transporte escolar e de passageiros em veículos com mais de dez lugares (PORTAL BRASIL, 2012).

A Lei $n^{\circ} 12.619 / 2012$, foi um marco importante para o setor de transporte, pois trouxe uma grande mudança sobre o transporte rodoviário de cargas, especialmente no que se refere aos custos de tempo e de viagem (REIS, 2013).

Em contrapartida, estimativas indicam que devido a redução da quilometragem rodada ao mês, haverá aumento do prazo de entrega de mercadorias em aproximadamente $56 \%$, devido ao fato que o veículo demorará mais tempo para concluir o mesmo percurso (DECOPE, 2012).

\subsection{Objetivo do Trabalho}

Este trabalho tem por objetivo desenvolver uma análise da variação da quantidade de indenizações pagas por morte no transporte rodoviário de cargas. Em suma, busca-se responder aos seguintes questionamentos:

i) Existe relação entre o aumento da frota de caminhões circulantes e o número de acidentes resultantes em mortes?

ii) Há melhora das condições de pavimentação das vias rodoviárias? Se sim, essa melhora traz impactos para o nível de acidentes com mortes que geram indenizações?

Para a consecução deste objetivo geral foram estabelecidos os seguintes objetivos específicos:

Realizar a revisão bibliográfica, abrangendo o modal rodoviário com destaque para a logística de transporte, a Lei do Descanso e a revisão da Lei do Descanso;

Estudar o impacto da lei do descanso no modal rodoviário em relação aos acidentes com ênfase no transporte de carga;

Levantar dados necessários para elaboração da analise entre os anos de 2015 e 2018;

Desenvolver análise estatística dos dados levantados.

\subsection{Proposta Metodológica}

A pesquisa é um procedimento formal, que se utiliza de método de pensamento reflexivo, solicita um trato científico e se constitui no meio para se pôr a par da realidade ou descobrir verdades parciais (MARCONI\&LAKATOS, 1985).

A metodologia de pesquisa escolhida foi estruturada sobre quatro pilares: quanto a sua natureza, abordagem, objetivos e procedimentos técnicos, conforme descrito na Figura 1. 


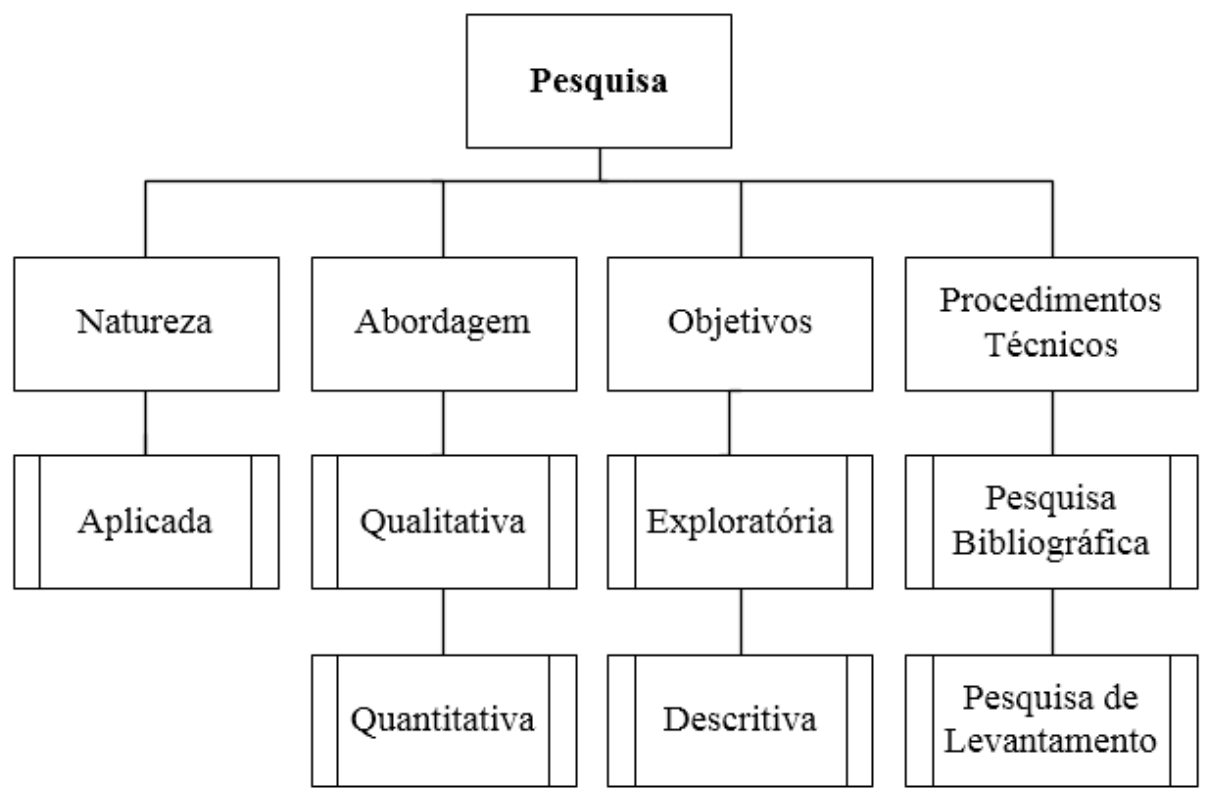

Figura 1. Proposta metodológica. Fonte: Adaptada de Santos (2010)

Quanto a natureza, decidiu-se por adotar uma pesquisa aplicada. De acordo com Barros e Lehfeld (2000) a pesquisa aplicada é motivada pela necessidade de gerar conhecimentos aplicáveis de maneira prática na solução de problema do mundo real. Appolinario (2004) destaca que o objetivo da pesquisa aplicada é a resolução de problemas ou carências tangíveis e imediatos.

Optou-se pela abordagem quantitativa e qualitativa, pois, segundo Richardson $(1999$, p. 80), as pesquisas que utilizam método qualitativo de estudo podem retratar a complexidade de um problema e analisar relação de certas variáveis. Já a pesquisa quantitativa, conforme Richardson (1999, p.70), tem por característica o emprego de qualificação dos tipos de coleta de informações, realizando o tratamento destas usando técnicas estatísticas, como coeficiente de correlação, análise de regressão entre outros.

Optou-se pelos objetivos descritivo e exploratória para o desenvolvimento deste trabalho, pois, conforme Gil (1999) a pesquisa exploratória se desenvolve na direção de proporcionar uma visão ampla acerca de determinado fato. Logo, este tipo de pesquisa é realizado, principalmente, quando o tema é pouco explorado e é difícil formular conjecturas exatas e praticáveis. Andrade (2002) enfatiza que a pesquisa descritiva se atenta em observar os fatos, registra-los, analisa-los, classifica-los e interpretá-los, sem interferência do investigador.

Para os procedimentos técnicos, optou-se inicialmente por uma pesquisa bibliográfica e pesquisa de levantamento. Segundo Fonseca (2002, p.32), todo trabalho cientifico começa com uma pesquisa bibliográfica, tornando possível ao investigador conhecer os estudos já realizados sobre o assunto. A pesquisa descritiva é a que mais se ajusta a pesquisa de levantamento, conforme Gil (2007, p.52).

\section{FUNDAMENTAÇÃO TEÓRICA}

\subsection{Transporte Rodoviário de Cargas}

Realizando uma comparação entre os diversos modais de transporte, o sistema rodoviário de cargas possui algumas vantagens: como o serviço porta-a-porta, onde a carga sai do local de origem diretamente para o seu destino, sem a necessidade de embarque e desembarque, durante o caminho; 
a agilidade e a disponibilidade do serviço; a capacidade de transportar todos os tipos de carga, bem como cargas de menor porte; entre outras (BALLOU, 2006).

A malha rodoviária brasileira possui aproximadamente 1,6 milhão de quilômetros de extensão, entre rodovias pavimentadas e não pavimentadas, com uma densidade de $0,2 \mathrm{~km} / \mathrm{km} 2$ de área do País. Nas regiões sul e sudeste onde se concentram 73\% do PIB (Produto Interno Bruto), estão localizadas mais da metade das estradas. Cerca de $80 \%$ das rodovias estão sob jurisdição municipal (1,28 milhão de quilômetros), sendo a restante responsabilidade do Governo Federal e dos Estados -76 mil km e 220 mil km, respectivamente (BRASIL, 2011).

Para que uma empresa atue no sistema rodoviário brasileiro, como transportadora de cargas, esta depende de prévia inscrição no Registro Nacional de Transportadores Rodoviários de Carga (RNTRC). A atividade econômica do transporte rodoviário de cargas realizado em vias públicas, no território nacional, por conta de terceiros e mediante remuneração, exercido por pessoa física ou jurídica em regime de livre concorrência, conforme estabelecido na Lei n ${ }^{\circ} 11.442 / 2007$ (BRASIL, 2007). A Tabela 1 demonstra a quantidade de transportadores e o tamanho das frotas registrados na base de dados do RNTRC para maio de 2018 (ANTT, 2018a).

Tabela 1. Quantitativos de transportadores registrados na base de dados do RNTRC

\begin{tabular}{lccc}
\hline Tipo do Transportador & Registros Emitidos & Veículos & Veículos/ Transportador \\
\hline Autônomo & 481.761 & 660.476 & 1,4 \\
Empresa & 144.455 & 1.084 .529 & 7,5 \\
Cooperativa & 327 & 22.891 & 70 \\
Total & 626.543 & 1.767 .896 & 2,8 \\
\hline
\end{tabular}

Fonte: Site da Agencia Nacional de Transportes Terrestres (2018)

A Tabela 2 demonstra a relação entre tipos de veículos de carga por número de veículos registrados no RNTRC, proporcionando numa visão geral do tamanho da frota de veículos de carga (ANTT, 2018b).

Tabela 2. Relação tipos de veículo de carga por número de veículos registrados

\begin{tabular}{|c|c|c|c|c|}
\hline Tipo de Veículo & Autônomo & Empresa & Coope rativa & Total \\
\hline CAMINHÃO LEVE (3,5T A 7,99T) & 70009 & 49038 & 1075 & 120122 \\
\hline CAMINHÃO SIMPLES (8T A 29T) & 251798 & 220945 & 3728 & 476471 \\
\hline CAMINHÃO TRATOR & 141284 & 298951 & 7766 & 448001 \\
\hline CAMINHÃO TRATOR ESPECIAL & 585 & 1533 & 38 & 2156 \\
\hline CAMINHONETE / FURGÃO (1,5T A 3,49T) & 50472 & 29315 & 378 & 80165 \\
\hline REB/MIMADO IRM NB & 2 & 6 & 0 & 8 \\
\hline REBOQUE & 8556 & 29371 & 302 & 38229 \\
\hline SEMI-REBOQUE & 124155 & 445502 & 9339 & 578996 \\
\hline SEMI-REBOQUE COM 5a RODA / BITREM & 443 & 1123 & 74 & 1640 \\
\hline SEMI-REBOQUE ESPECIAL & 154 & 1173 & 8 & 1335 \\
\hline UTILITÁRIO LEVE (0,5T A 1,49T) & 12677 & 6940 & 179 & 19796 \\
\hline VEÍCULO OPERACIONAL DE APOIO & 341 & 632 & 4 & 977 \\
\hline TOTAL & 660.476 & 1.084 .529 & 22.891 & 1.767 .896 \\
\hline
\end{tabular}

Fonte: Site da Agencia Nacional de Transportes Terrestres (2018)

\subsection{Causas de Acidente no Transporte Rodoviário}


O excesso de carga provoca reduções de até $50 \%$ na durabilidade dos pavimentos e reduz a capacidade de segurança dos componentes mecânicos e estruturais do veículo, notadamente no sistema de frenagem (ALBANO, 2005).

Conforme Moraes (2012) em cada três motoristas rodoviários de carga, um utiliza substâncias químicas ou entorpecentes para suportar as longas jornadas de trabalho. $\mathrm{O}$ fato é que, um motorista cansado, correndo, não está mais em condição de reagir adequadamente aos imprevistos do percurso (PAMCARY, 2007).

Os dados das Tabela 3 e 4, abrangem aos acidentes envolvendo caminhões, nas rodovias federais nas suas diversas causas e categoria de vítimas (ATLAS DA ACIDENTALIDADE TRANSPORTE BRASILEIRO, 2018), visando determinar o tamanho da acidentalidade nas rodovias brasileiras. A análise estatística realizada considerou os acidentes registrados pela Polícia Rodoviária Federal (PRF).

Tabela 3. Distribuição de acidentes por causa, valores absolutos 2016

\begin{tabular}{|c|c|c|c|c|c|c|c|}
\hline Causa & Acidentes & Pessoas envolvidas & Ilesos & Feridos Leves & Feridos graves & Mortes & Ignorados \\
\hline Defeito mecânico em veículo & 2221 & 4037 & 2848 & 751 & 246 & 82 & 110 \\
\hline Defeito na via & 402 & 753 & 451 & 195 & 57 & 31 & 19 \\
\hline Desobediência à sinalização & 1120 & 3048 & 1736 & 689 & 329 & 158 & 136 \\
\hline Dormindo & 1581 & 3033 & 1694 & 841 & 261 & 162 & 75 \\
\hline Falta de atenção & 7331 & 18043 & 11902 & 3664 & 1322 & 521 & 634 \\
\hline Ingestão de álcool & 967 & 2299 & 1351 & 475 & 232 & 113 & 128 \\
\hline Não guardar distância de segurança & 2049 & 5932 & 4377 & 1000 & 213 & 61 & 281 \\
\hline Ultrapassagem indevida & 1010 & 3135 & 1680 & 698 & 367 & 252 & 138 \\
\hline Velocidade incompatível & 3511 & 7101 & 3770 & 1923 & 739 & 424 & 245 \\
\hline Animais na Pista & 320 & 522 & 402 & 78 & 21 & 11 & 10 \\
\hline Outras & 6559 & 14007 & 8050 & 3081 & 1203 & 817 & 856 \\
\hline
\end{tabular}

Fonte: Site Atlas da Acidentalidade Transporte Brasileira (2018)

Tabela 4. Distribuição anual de acidentes

\begin{tabular}{lcccccccccc}
\hline Categorias & $\mathbf{2 0 0 7}$ & $\mathbf{2 0 0 8}$ & $\mathbf{2 0 0 9}$ & $\mathbf{2 0 1 0}$ & $\mathbf{2 0 1 1}$ & $\mathbf{2 0 1 2}$ & $\mathbf{2 0 1 3}$ & $\mathbf{2 0 1 4}$ & $\mathbf{2 0 1 5}$ & $\mathbf{2 0 1 6}$ \\
\hline Pessoas envolvidas & 94565 & 107400 & 114121 & 136903 & 143302 & 135902 & 141144 & 124142 & 83175 & 61910 \\
Ilesos & 69242 & 79485 & 85113 & 103881 & 109241 & 103145 & 107738 & 92067 & 57268 & 38261 \\
Feridos Leves & 14072 & 14710 & 15358 & 17333 & 17835 & 17476 & 17980 & 17210 & 14587 & 13395 \\
Feridos Graves & 6561 & 6765 & 6868 & 7438 & 7410 & 7021 & 6733 & 6738 & 5263 & 4990 \\
Mortes & 3015 & 3076 & 3106 & 3649 & 3861 & 3674 & 3644 & 3538 & 2809 & 2632 \\
Ignorados & 1675 & 3364 & 3676 & 4602 & 3861 & 3674 & 3644 & 3538 & 2809 & 2632 \\
Número médio de mortes & 8,3 & 8,4 & 8.5 & 10 & 10,6 & 10,1 & 10 & 9,7 & 7,7 & 7,2 \\
Total de acidentes & 44853 & 50149 & 53052 & 63031 & 66397 & 62867 & 64385 & 56422 & 37376 & 27071 \\
\hline
\end{tabular}

Fonte: Site Atlas da Acidentalidade Transporte Brasileiro (2018)

O Boletim de Acidentes nas rodovias federais elaborado pela Confederação Nacional do Transporte (CNT), apresentado na Tabela 5, traz informações sobre a estimativa dos custos econômicos das ocorrências, de acordo com o tipo: sem vítima, com vítimas e com fatalidade. Custo este superior ao investimento realizado nas rodovias no ano anterior, que foi de R \$8,61 bilhões (CNT, 2017). 
Tabela 5. Custo econômico dos acidentes 2016

\begin{tabular}{lccc}
\hline Tipo de Acidente & Custo Médio (R\$) & Número de acidentes & Custo Total (R\$ bilhões) \\
\hline Com fatalidade & $\mathrm{R} \$ 760.794,64$ & 5355 & $\mathrm{R} \$ 4,07$ \\
Com vitimas & $\mathrm{R} \$ 106.082,96$ & 54873 & $\mathrm{R} \$ 5,82$ \\
Sem vítimas & $\mathrm{RS} \mathrm{27,129,24}$ & 36135 & $\mathrm{R} \$ 0,98$ \\
Total & & 96363 & $\mathrm{R} \$ 10,88$ \\
\hline
\end{tabular}

Fonte: Site da Confederação Nacional do Transporte (2017)

Estudo do Instituto de Pesquisa Econômica Aplicada (IPEA, 2015b) revelou que o transporte de cargas é responsável por 33,4\% dos acidentes ocorridos nas rodovias em 2014.

De acordo com o Anuário Estatístico de Acidentes de Trabalho, de 2015, o setor de transporte rodoviário de cargas representa cerca de $11 \%$ dos acidentes fatais acontecidos no Brasil. Em 2015, o número de óbitos a cada 100 mil trabalhadores no setor foi de 29,93. Enquanto isso, a média no país foi de 5,79 a cada 100 mil trabalhadores (BRASIL, 2017).

\subsection{Lei do Descanso (Lei $N^{\circ}$ 12.619)}

Em vigência desde o ano de 2012, a Lei n ${ }^{\circ} 12.619$, conhecida como Lei do Descanso, trouxe inúmeras regulamentações sobre o trabalho dos motoristas e ajudantes do transporte rodoviário de cargas. Esse capítulo traz, de forma sucinta, uma pesquisa sobre os avanços promovidos pela lei no que tange aos esforços para promover melhor condição de trabalho.

Michel (2008) salienta que a legislação concernente à prevenção aos riscos de acidentes de trabalho foi se moldando até chegar à chamada teoria do risco social, cabe dizer, o acidente de trabalho é um risco inerente a qualquer atividade profissional, atividade esta que se exerce em prol de todos, motivo pelo qual a sociedade deve amparar as vítimas de acidente. Moraes (2012) separa, ainda, o ambiente de trabalho dos motoristas rodoviários em ambiente do empregador e ambiente de terceiros, subdividindo este em ambientes de terceiros privados e públicos, atestando que o meio ambiente laboral, enquanto proveniente do meio ambiente artificial, constitui condição primordial para que o trabalhador exerça suas atividades com qualidade de vida.

Anteriormente a lei do descanso, não existia nenhum tipo de controle sobre a jornada de trabalho dos motoristas de cargas. Segundo Lucas (2012) os motoristas não tinham direito sobre a jornada de trabalho e a CLT não era cumprida quando se tratava de motoristas.

Rodrigues (2009) explana também sobre o uso de estimulantes, para driblar a fadiga imposta por uma jornada de trabalho desumana e cruel, bem como a falta de paradas de descanso adequada, impostas aos motoristas profissionais de transporte de carga. O Ministério dos Transportes (MT) em integração com a Agencia Nacional de Transportes Terrestres (ANTT) e o Departamento Nacional de Infraestrutura de Transportes (DNIT), são responsáveis pela execução do levantamento e divulgação dos trechos de rodovias federais que dispõem de locais adequados para a parada e descanso com segurança dos motoristas profissionais, conforme dos ditames da portaria $\mathrm{n}^{\circ} 944$ de junho de 2015, do Ministério do Trabalho e Emprego (MTE), atendendo as determinações da lei $\mathrm{n}^{\circ}$ 13.103/2015, a nova lei do caminhoneiro (ANTT, 2018c). Essa Lei revoga alguns aspectos da Lei do descanso que serão detalhados a seguir.

Segundo Moraes (2015) a Lei $\mathrm{n}^{\circ} 13.103 / 2015$ promoveu um sério retrocesso na regulamentação das atividades dos motoristas profissionais. Ainda ressalta que a Lei $\mathrm{n}^{\circ}$ 13.103/2015 abalou os pilares edificados na Lei $n^{\circ}$ 12.619/2012, os quais são: a limitação da jornada, a vedação ao pagamento por comissão e a garantia de remuneração digna ao motorista. 


\section{LEVANTAMENTO DADOS}

Para o desenvolvimento do trabalho foi elaborada uma série histórica de dados com as variáveis: porcentagem da malha rodoviária pavimentada, frota nacional de caminhões e indenizações por morte em acidentes com caminhões. Delimitou-se o período observado aos anos de 2015 a 2018.

Os dados relativos as variáveis: porcentagem da malha rodoviária pavimentada e frota nacional de caminhões foram coletados nos boletins estatísticos da base de dados da Confederação Nacional de Transporte (CNT, 2018).

Os dados relativos a variável: indenizações por morte em acidentes com caminhões foram coletados nos boletins estatísticos da base de dados da Seguradora Líder-DPVAT (DPVAT, 2018).

Os dados estão disponíveis na Tabela 6.

Tabela 6. Série Histórica

\begin{tabular}{cccc}
\hline Ano & $\begin{array}{c}\text { \% Malha } \\
\text { Rodoviária } \\
\text { Pavimentada }\end{array}$ & $\begin{array}{c}\text { Frota Nacional de } \\
\text { Caminhões (unid.) }\end{array}$ & $\begin{array}{c}\text { Indenizações por } \\
\text { Morte, Acidente } \\
\text { com Caminhões }\end{array}$ \\
\hline $20151^{\mathbf{o}} \mathrm{sem}$. & 12,24 & 2.599 .527 & 2027 \\
$20152^{\mathbf{o}} \mathrm{sem}$. & 12,29 & 2.645 .992 & 1872 \\
$20161^{\mathbf{o}} \mathrm{sem}$. & 12,24 & 2.665 .192 & 1658 \\
$20162^{\mathbf{o}} \mathrm{sem}$. & 12,28 & 2.677 .957 & 1537 \\
$20171^{\circ} \mathrm{sem}$. & 12,32 & 2.675 .023 & 1877 \\
$20172^{\mathbf{o}} \mathrm{sem}$. & 12,31 & 2.716 .258 & 1963 \\
$20181^{\circ} \mathrm{sem}$. & 12,32 & 2.733 .221 & 1982 \\
\hline
\end{tabular}

Fonte: Site da Confederação Nacional do Transporte (2018) e Seguradora Lider-DPVAT (2018)

\section{ANÁLISE DE RESULTADOS}

Observando o Gráfico 1, constata-se que há uma pequena tendência de crescimento das indenizações. Porém há indícios que essa variável possa ser considerada estacionária, principalmente pelo baixo $\mathrm{R}^{2}$ de sua tendência pelo tempo. Em outro aspecto, no mesmo período em que houve significativo aumento da frota de caminhões e melhora na malha rodoviária os níveis de indenização estão praticamente estagnados.

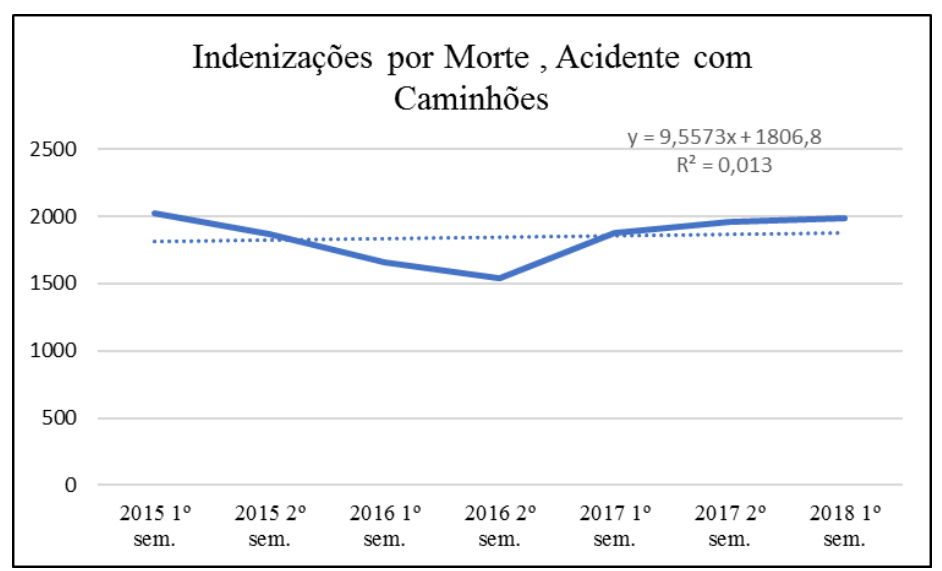

Gráfico 1. Indenizações por Morte, Acidente com Caminhões. Fonte: Autores (2018) 
Antes de estimar os modelos de regressão linear, foi realizada a análise do grau de correlação entre as variáveis. Esta análise foi realizada na ferramenta de análise de dados da planilha eletrônica Microsoft Excel através da opção Dados/Análise de dados /correlação, gerando os resultados que podem ser observados na Tabela 7.

Tabela 7. Correlação entre as variáveis

\begin{tabular}{|c|c|c|c|}
\hline & $\begin{array}{c}\text { \% Malha } \\
\text { Rodoviaria } \\
\text { Pavimentada }\end{array}$ & $\begin{array}{l}\text { Frota Nacional } \\
\text { de Caminhões } \\
\text { (unid.) }\end{array}$ & $\begin{array}{l}\text { Indenizações por } \\
\text { Morte, Acidente } \\
\text { com Caminhões }\end{array}$ \\
\hline \% Malha Rodoviaria Pavimentada & 1 & & \\
\hline $\begin{array}{l}\text { Frota Nacional de Caminhões (unid.) } \\
\text { Indenizações por Morte, Acidente com }\end{array}$ & 0,722808163 & 1 & \\
\hline Caminhões & 0,245229494 & $-0,014773449$ & \\
\hline
\end{tabular}

Fonte: Autores (2018)

Pelos resultados da Tabela 7, pode-se observar que não é possível confiar no impacto do aumento da frota de caminhões sobre a quantidade de indenizações pagas por acidente envolvendo caminhões, onde se apresenta um índice de correlação insignificante (-0,014773449). Esse resultado corrobora com o fato das duas variáveis possuírem comportamentos distintos ao longo do tempo. O que nos leva a intuir que a modernização e regulamentação da atividade de transporte de cargas através da lei do descanso está surtindo um efeito benéfico na diminuição dos índices de mortes por acidente envolvendo caminhões. Visto que há aumento significativo da frota de veículos.

Existe uma correlação positiva bem forte $(0,722808163)$ entre a porcentagem da malha pavimentada e o aumento da frota. Ambas apresentam comportamento semelhante e crescem numa proporção muito próxima.

A análise entre a malha pavimentada e a quantidade de indenizações apresenta uma correlação não tão significante $(0,245229494)$ enquanto uma cresce $100 \%$ a outra cresce $24 \%$.

A estimação do modelo de regressão linear foi realizada através da ferramenta de análise de dados da planilha eletrônica Microsoft Excel. Considerando a variável dependente: indenizações por Morte, Acidente com Caminhões. Na Tabela 8 é demonstrado uma regressão linear simples, considerando apenas a variável independente: Frota Nacional de Caminhões (unid.) e a variável dependente: indenizações por morte, acidente com caminhão.

Tabela 8. Modelo I de regressão linear

\begin{tabular}{lr}
\hline \multicolumn{2}{c}{ Estatística de regressão } \\
\hline R-Quadrado & 0,000218255 \\
Observações & 7 \\
\hline
\end{tabular}

\begin{tabular}{lcc}
\hline & Coeficientes & valor-P \\
\hline Interseção & 2007,190884 & 0,69951995 \\
& - & \\
Frota Nacional de Caminhões (unid.) & 0,000060654 & 0,97492255 \\
\hline
\end{tabular}

Fonte: Autores (2018) 
$\mathrm{Na}$ análise de regressão do modelo I é possível constatar o respectivo $\mathrm{R}^{2}$ com valor muito baixo, R-Quadrado igual a 0,000218255. Nesta situação a variável, indenizações por Morte, Acidente com Caminhões, não pode ser explicada pela variável, Frota Nacional de Caminhões (unid.).

$\mathrm{O}$ valor $=\mathrm{P}(0,97492255)$ da variável Frota Nacional de Caminhões (unid.). indica que a regressão não é significativa e a variável não pode ser usada para explicar a variável indenizações por Morte, Acidente com Caminhões.

Na Tabela 9 é demonstrado uma regressão linear simples, considerando apenas a variável independente: \% Malha Rodoviária Pavimentada e a variável dependente: indenizações por morte, acidente com caminhão.

Tabela 9. Modelo II de regressão linear

\begin{tabular}{lr}
\hline \multicolumn{2}{c}{ Estatística de regressão } \\
\hline R-Quadrado & 0,060137505 \\
Observações & 7 \\
\hline
\end{tabular}

\begin{tabular}{lcc}
\hline & Coeficientes & valor-P \\
\hline & \multicolumn{2}{c}{-} \\
Interseção & 13995,78079 & 0,638469939 \\
\% Malha Rodoviária Pavimentada & 1289,266513 & 0,596089795 \\
\hline
\end{tabular}

Fonte: Autores (2018)

$\mathrm{Na}$ análise de regressão do modelo II é possível constatar o respectivo $\mathrm{R}^{2}$ com valor muito baixo, R-Quadrado igual a 0,060137505. Nesta situação a variável, indenizações por Morte, Acidente com Caminhões, não pode ser explicada pela variável, \% Malha Rodoviária Pavimentada.

O valor=P $(0,596089795)$ da variável \% Malha Rodoviária Pavimentada. indica que a regressão não é significativa e a variável não pode ser usada para explicar a variável indenizações por Morte, Acidente com Caminhões.

\section{CONSIDERAÇÕES FINAIS}

O presente trabalho teve como objetivo identificar o impacto do crescimento da frota de caminhões e a variação porcentual de rodovias pavimentadas sobre a variação das indenizações pagas por morte envolvendo caminhões, no período estudado. Constatou-se que as bases de dados da Seguradora Líder-DPVAT e da Confederação Nacional de Transportes (CNT) não apresentavam disponíveis os dados de anos anteriores ao período proposto para análise.

Os dados levantados consistem em informações acumuladas em períodos semestrais, que vão do primeiro semestre de 2015 até o primeiro semestre de 2018. Através da construção do modelo de regressão foi possível inferir no efeito da variação da frota e a variação porcentual de rodovias pavimentação das rodovias sobre o número de indenizações pagas por acidente envolvendo caminhões.

Através da análise realizada foi constado uma relação muito fraca entre o crescimento da frota de caminhões e as indenizações pagas, não sendo possível assim explicar os níveis de indenização pagas por morte envolvendo caminhões. A frota cresceu, porém, o número de indenizações pagas apresentaram uma redução e uma certa estabilidade no período.

A evolução da malha rodoviária pavimentada registrada no período, foi gradativa, porém não muito expressiva, não trazendo grande impacto sobre os níveis de indenizações pagas. Uma malha pavimenta proporciona um melhor desempenho do caminhão, podendo levar ao aumento da 
velocidade e os riscos pertinentes, bem como, evitar acidentes por colisão e outros próprios das vias debilitadas.

Conclui-se, portanto, que não existe efeito significativo entre as variáveis dependente e independentes estuda neste trabalho.

A pesquisa bibliográfica nos possibilitou verificar que o comportamento profissional do caminhoneiro e a sua adequada regulação através da lei do descanso, proporcionou resultados muito interessantes quanto a diminuição de acidentes e consequentemente na redução de indenizações pagas por morte envolvendo caminhões.

Para futuras pesquisas recomenda-se a buscar outras variáveis que possam ajudar na explicação dos níveis de indenizações pagas por morte envolvendo caminhões.

\section{REFERÊNCIAS BIBLIOGRÁFICAS}

ABRAMET. Associação Brasileira de Medicina de Tráfego. Pobre profissional ao volante. 2012. Disponível em http://www.abramet.com.br/conteudos/artigos/pobre_profissional_do_volante/. Acesso em: 31/05/2018.

ALBANO, J. F. 2005. Tese (Doutorado em Sistemas de Transporte e Logística). Efeitos dos Excessos de Carga sobre a Durabilidade de Pavimentos. Escola de Engenharia, Programa de Pós-Graduação em Engenharia de Produção, Universidade Federal do Rio Grande do Sul. Anais... Acesso em 27/05/2018.

ANDRADE, M. M. Como preparar trabalhos para cursos de pós-graduação: noções práticas. 5. ed. São Paulo: Atlas, 2002.

ANTT. Agência Nacional de Transporte Terrestre. Transportadores - Frota de Veículos. 2018a. Disponível em http://portal.antt.gov.br/index.php/content/view/20270/ Transportadores__Frota_de_Veiculos.html. Acesso em: 30/05/2018.

ANTT. Agência Nacional de Transporte Terrestre. Transportadores - Frota de Veículos Tipos de Veículo. 2018b. Disponível em http://portal.antt.gov.br/index.php/content/view/20271/ Transportadores__Frota__Tipo_de_Veiculo.html. Acesso em: 30/05/2018.

ANTT. Agência Nacional de Transporte Terrestre. Pontos de Parada e Descanso. 2018c. Disponível em http://www.antt.gov.br/rodovias/Pontos_de_Parada_e_Descanso.html. Acesso em: 29/05/2018.

APPOLINÁRIO, F. Dicionário de metodologia científica: um guia para a produção do conhecimento científico. São Paulo: Atlas, 2004.

Atlas da Acidentalidade no Transporte Brasileiro. Distribuição de acidentes por causa, levantamento 2015. 2015. Disponível em http://www.atlasacidentesnotransporte.com.br/ consulta?grafico=acidente\#graph. Acesso em: 28/05/2018.

BALLOU, R. H.; Gerenciamento da cadeia de suprimentos/logística empresarial. 5. ed. - Porto Alegre: Bookman, 2006.

BARROS, A. J. S.; LEHFELD, N. A. S. Fundamentos de metodologia: um guia para a iniciação cientifica. 2. Ed. São Paulo: Makron Books, 2000. 
BRASIL, Departamento Nacional de Infraestrutura de Transportes(DNIT), PNV. 2011.

BRASIL. Lei N 11.442, DE 5 DE JANEIRO DE 2007. Dispõe sobre o transporte rodoviário de cargas por conta de terceiros e mediante remuneração e revoga a Lei no 6.813 , de 10 de julho de 1980. Disponível em http://www.planalto.gov.br/CCIVIL_03/_Ato20072010/2007/Lei/L11442.htm. Acesso em: 30/05/2018.

BRASIL, Ministério do Trabalho e Emprego(MTE). Brasil tem mais de 900 mil profissionais com registro em carteira de trabalho. 2017. Disponível em http://trabalho.gov.br/noticias/4998-brasiltem-mais-de-900-mil-profissionais-com-registro-em-carteira-de-trabalho. Acesso em: 31/05/2018.

CNT. Confederação Nacional do Transporte. Boletim de acidentes. 2017. Disponível em http://www.cnt.org.br/Boletim/boletim-acidentes-cnt. Acesso em: 30/05/2018.

CNT. Confederação Nacional do Transporte. Boletim de estatístico. 2018. Disponível em http://www.cnt.org.br/Boletim/boletim-acidentes-cnt. Acesso em: 30/06/2018.

DECOPE. Departamento de Custos Operacionais, Estudos Técnicos e Econômicos. Disponível em http://www.ntc.org.br. Acesso em 25/03/2018.

DENATRAN. Departamento Nacional de Trânsito. Resoluções. Disponível em: http://www.denatran.gov.br/resolucoes. Acesso em 30/06/2018.

DPVAT. SEGURADORA LIDER-DPVAT. Boletim estatístico. 2018. Disponível em https://www.seguradoralider.com.br/Centro-de-Dados-e-Estatisticas/Boletim-Estatistic. Acesso em: $30 / 06 / 2018$.

FONSECA, J.J.S. Metodologia da pesquisa cientifica. Fortaleza: UEC, 2002. Apostila.

GIL, A.C. Como elaborar projetos de pesquisa. 4.ed. São Paulo: Atlas, 2007.

GIL, A. C. Métodos e técnicas de pesquisa social. 5. ed. São Paulo: Atlas, 1999.

IPEA. Instituto de Pesquisa Econômica Aplicada. Estimativa dos Custos dos Acidentes de Trânsito no Brasil com Base na Atualização Simplificada das Pesquisas Anteriores do Ipea - Relatório de Pesquisa. Brasília: IPEA 2015a. Disponível em http://repositorio.ipea.gov.br/bitstream/11058/7456/1/RP_Estimativa_2015.pdf. Acesso em: 03/05/2018.

IPEA. Instituto de Pesquisa Econômica e Aplicada. Acidentes de trânsito nas rodovias federais brasileiras. Caracterização, tendências e custos para a sociedade. Relatório de pesquisa. Brasília: IPEA 2015b. Disponível em http:// www.viasseguras.com.br/IPEA/Pesquisa2015. Acesso em: $31 / 05 / 2018$.

LUCAS A. Palestra do Procurador do Trabalho Adélio Lucas dá início ao segundo dia do evento. $2012 . \quad$ Disponível em http://www.fetropar.org.br/index.php?option=com_content\&view=article\&id=10832:comecao- 
segundo-dia-do-X-seminario-juridico-e-de-dirigentes-

sindicais\&catid=340: materias\&Itemid=100214. Acesso em: 0202/05/2018.

MARCONI, M. D., \& LAKATOS, E. M. (1985). Fundamentos de Metodologia Científica. São Paulo: Editora Atlas.

MICHEL, O. Acidentes do trabalho e doenças ocupacionais. 3. ed. São Paulo: LTr, 2008.

MORAES, P.D.A. de. Abordagem holística sobre nova regulamentação da profissão do motorista (Lei 12.619/2012). Trabalho Encarte, Curitiba, n. 185, p. 6789-6806, jul. 2012.

MORAES, P. D. A. de. Impactos da Lei n. 13.103/2015 sobre a proteção jurídica ao motorista profissional. Revista eletrônica [do] Tribunal Regional do Trabalho da 9a Região, Curitiba, PR, v. 5, n. 45, p. 50-79, out. 2015. Disponível em https://hdl.handle.net/20.500.12178/89346. Acesso em: $23 / 05 / 2018$.

REIS, C.R. Análise de viabilidade do transporte marítimo de cabotagem na comercialização de arroz da região sul para o nordeste brasileiro. Monografia apresentada para obtenção do grau de especialista no curso de Gestão Empresarial da Universidade do Extremo Sul Catarinense, UNESC. Anais... CRICIUMA: 2013.

RICHARDSON, R. J. Pesquisa social: métodos e técnicas. 3. Ed. São Paulo: Atlas, 1999.

RODRIGUES, J. N. Tempo ao volante: uma abordagem sociológica da jornada de trabalho de motoristas rodoviários. 2009. Disponível em http://www.estradas.com.br/sosestradas/articulistas/nivaldino/tempo_ao_volante.asp. Acesso em: 20/04/2018.

SANTOS, R. F. Proposta de um modelo de gestão integrada da cadeia de suprimentos: aplicação no segmento de eletrodomésticos. 2010. 202f. Dissertação (Doutorado em Ciência no Curso de Engenharia Aeronáutica e Mecânica, Área de Produção) - ITA - Instituto Tecnológico de Aeronáutica, Anais... São José dos Campos, 2010.

SILVA, L. G. da. O trabalho dos motoristas de caminhão: a relação entre atividade, vínculo empregatício e acidentes de trabalho. 2011. Dissertação (Mestrado em Saúde Ambiental) - Faculdade de Saúde Pública, Universidade de São Paulo, São Paulo, 2011. Anais... Disponível em http://www.teses.usp.br/teses/disponiveis/6/6134/tde-24022011-111659/. Acesso em:16/03/2018.

PAMCARY. Um diagnóstico de acidentes de caminhões. 2007. Disponível em http://viasseguras.com/content/download/302/1542/file/

Um\%20diagnostico\%20Acidentes\%20de\%20caminh\%C3\%B5es.pdf. Acesso em: 05/05/2018.

POLICIA RODOVIÁRIA FEDERAL. Disponível em http://www.dprf.gov.br. Acesso em 15/03/2018.

PORTAL BRASIL. Disponível em http://brasil.gov.br/. Acesso em 15/05/2018. 